Indranil Sen MBBS, MS Ankur Mukherjee MBBS, MS Jayanta Saha MBBS, MS Satadal Mandal MBBS, MS Ramanuj Sinha MS, DNB

Department of Otorhinolaryngology R. G. Kar Medical College and Hospital Kolkata, West Bengal, India
Correspondence: Dr. Ankur Mukherjee Room no-7, K B Hostel

R. G. Kar Medical College \& Hospital

1, Khudiram Bose Sarani, Kolkata -700004

India

Phone: (+91) 9434381027

Fax: (+91) 3328281551

Email:ankurdoc007@gmail.com

Reprints will not be available from the author.

The authors declared that this represents original material that is not being considered for publication or has not been published or accepted for publication elsewhere, in full or in part, in print or electronic media; that the manuscript has been read and approved by all the authors, that the requirements for authorship have been met by each author, and that each author believes that the manuscript represents honest work.

Disclosures: The authors signed disclosures that there are no financial or other (including personal) relationships, intellectual passion, political or religious beliefs, and institutional affiliations that might lead to a conflict of interest.

\section{Bilateral Antro-Choanal Polyps in an Elderly Female} \author{
group.

\section{Methods:} \\ Design: Case report \\ Setting: Tertiary Government Hospital \\ Patient: One
}

ABSTRACT

Objective: To report the first case of primary bilateral antro-choanal polyps in the elderly age

Result: A 60-year-old, non-allergic female with progressive bilateral nasal obstruction was subsequently diagnosed with bilateral antro-choanal polyps. Endoscopic sinus surgery was performed and the patient remained asymptomatic on one year follow-up.

Conclusion: Antro-choanal polyps can occur bilaterally in the elderly age group. To the best of our knowledge, this is the first reported case of primary bilateral antro-choanal polyps in an elderly female.

\section{Keywords: antro-choanal polyp, bilateral, elderly, female}

Antro-Choanal Polyps [ACP] are benign, solitary lesions which arise from the mucosa of the maxillary sinus. The mucosa usually prolapses through the maxillary ostium and may protrude through the accessory ostium, if present. Antro-choanal polyps usually involve the middle meatus. They increase in size and gradually progress towards the choana and nasopharynx and typically appear as a smooth, pale or bluish solitary mass on anterior or posterior rhinoscopy. Antro-choanal polyps are generally recognized to represent approximately $4-6 \%$ of all nasal polyps and are more prevalent in the pediatric population. ${ }^{1}$

Killian was the first to describe this entity in $1906 .{ }^{2}$ It is nearly always unilateral and bilateral ACP is an extremely rare entity and seldom found in the literature. ${ }^{3.4,5}$, A Pubmed search of MEDLINE, using the search terms 'bilateral,' 'antrochoanal polyp'and 'elderly' did not yield any report of primary bilateral ACP in an elderly person. The oldest report of primary bilateral ACP was in a 24-year-old female ${ }^{6}$ while post-operative bilateral ACP was documented emerging from previously-performed inferior meatus antrostomies in a 45 -year-old female. ${ }^{7}$ We report what may be the first such case of primary bilateral ACP in an elderly female. 


\section{CASE REPORT}

A 60-year-old female presented with gradually progressive rightsided nasal obstruction over the last six years. She did not seek any medical advice until similar symptoms developed in the left nasal cavity over the last 2-3 months. There was no history of pain, itching, sneezing, nasal bleeding or any other type of discharge. There was no history of associated asthma or allergy.

On anterior rhinoscopy, smooth, pale, polypoidal masses were found in both nasal cavities. The choanae and nasopharynx were free from the polyps on posterior rhinoscopy. Nasal endoscopy showed the polypoidal masses arising from both maxillary sinuses and protruding from their natural ostia. Coronal non-contrast Computed Tomography (CT) scans revealed both maxillary sinuses filled with hypo-dense soft tissue shadows extending into the corresponding nasal cavities, typical of antro-choanal polyps. On both sides, the maxillary ostia were considerably widened. There were small amounts of retained secretions in the ethmoid sinuses but the frontal sinuses were clear. (Figure 1) Differential blood counts and serum immunoglobulins were within normal limits.

The polyps were removed from both sides via endoscopic sinus surgery under general anaesthesia. On visualising the sinus with a 4.0 $\mathrm{mm} 70$ degree nasal endoscope, the polyps were found to originate from the anterior and the lateral walls of the sinus cavities. The gross appearance of both specimens was bluish, smooth and boggy with

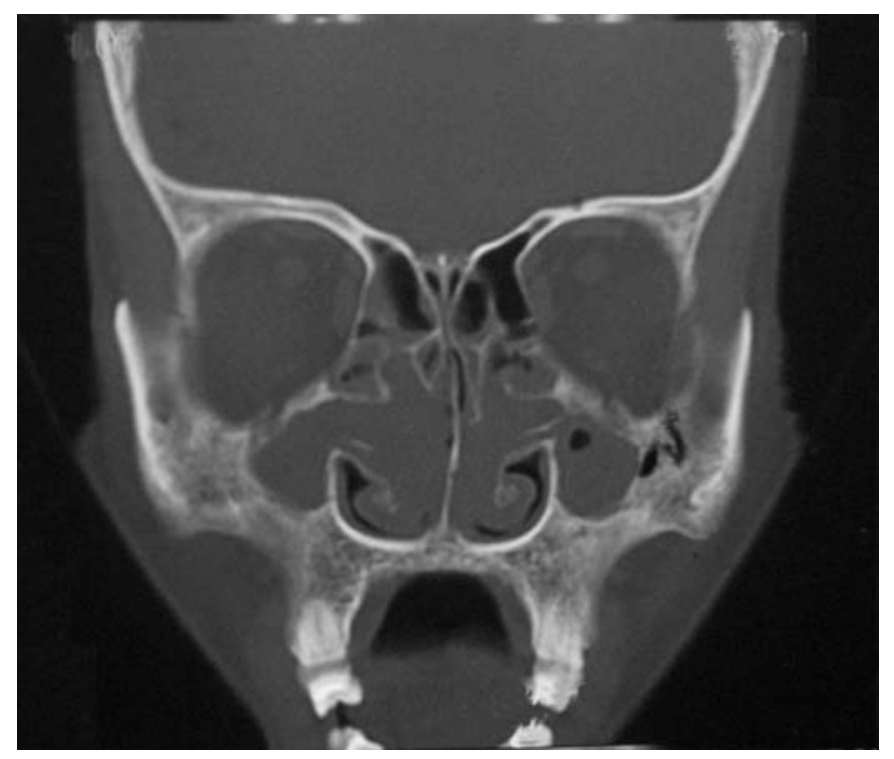

Figure 1. Coronal non-contrast CT scan showing both maxillary sinuses filled with hypo-dense soft tissue shadows extending into the corresponding nasal cavities, typical of antro-choanal polyps. Note considerable widening of both maxillary ostia and small amounts of retained secretions in the ethmoid sinuses. constrictions corresponding to the maxillary ostium. (Figure 2) The histopathologic report confirmed the diagnosis of benign allergic (antrochoanal) polyps. The patient remained symptom-free over a one year follow-up period.

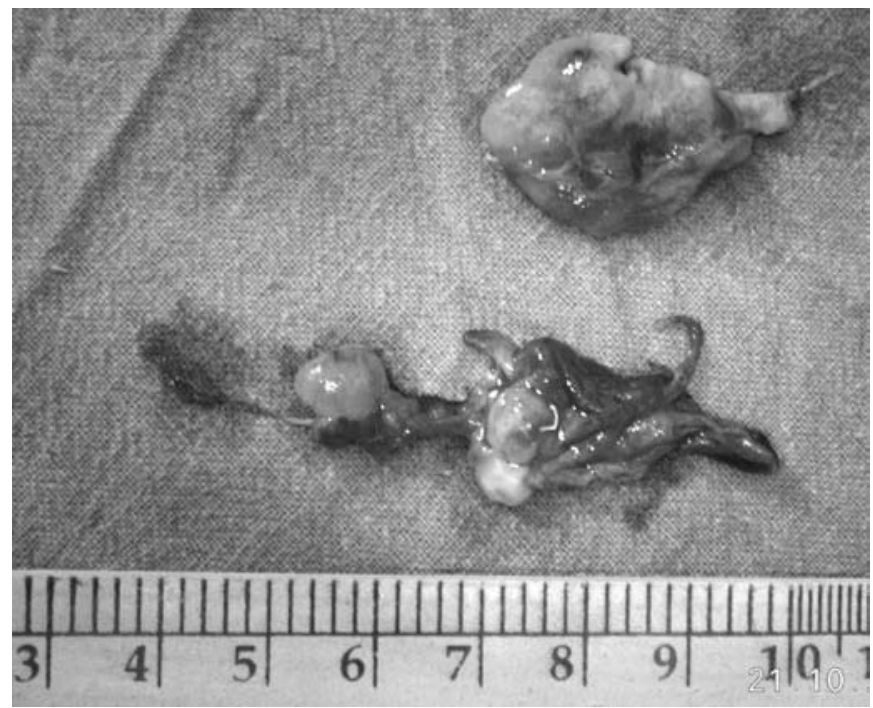

Figure 2. Photograph of both surgical specimens showing bluish, smooth and boggy character with constrictions corresponding to the maxillary ostia.

\section{DISCUSSION}

Antrochoanal polyps are thought to represent hypertrophic maxillary sinus mucosa prolapsing into the nasal cavity through the natural or accessory ostium. Although the natural history and site of origin of ACP was first reported by Killian in $1906,{ }^{2}$ the first description of ACP was made by Palfyn in $1753 .{ }^{2}$ Antro-choanal polyps are almost always unilateral and bilateral antrochoanal polyps are extremely rare. We found only three case reports in the literature ${ }^{3,6,8}$ with only one reported primary case in an adult. ${ }^{6}$ The largest series on ACP by Frosini et al. reported only three cases of bilateral ACP, but no age was given for those cases. ${ }^{2}$

The common clinical presentation of ACP is nasal obstruction, and ACP usually presents as a hypo-attenuating mass occupying the maxillary sinus on CT scans, which distinctly reveals its extension. ${ }^{9}$

No definite etiological factor for ACP has been found but chronic sinusitis, cystic fibrosis and allergy may have roles in its development. ${ }^{1,8}$ Look et al. postulated that $24 \%$ of ACP had the 'aspirin-sensitive asthma triad'.8.10

The treatment of ACP is surgical. The aim of surgery is to remove both the nasal and antral parts of the polyp as it tends to recur after 


\section{CASE REPORTS}

simple avulsion. The maxillary antrum should always be carefully inspected. Different approaches are recommended for this purpose, from the classical Caldwell-Luc approach"1 to the modified CaldwellLuc approach (intranasal antrostomy with resection of anterior part of inferior turbinate) ${ }^{12}$ and functional endoscopic sinus surgery (FESS). The Caldwell-Luc procedure may have possible side-effects including both anaesthesia and swelling of the cheek and also carries risks to the developing teeth in children. ${ }^{13}$ At present FESS is a very popular technique ${ }^{14.15}$ and if properly performed there is no recurrence and very few complications. ${ }^{10}$ Antro-choanal polyps originating from the anterolateral wall can be removed by a combined endoscopic and transcanine approach. $^{16}$

Antro-choanal polyps can occur bilaterally in the elderly age group. To the best of our knowledge, this is the first reported case of primary bilateral antro-choanal polyps in an elderly female.

1. Chen JM, Schloss MD, Azouz ME. Antrochoanal polyp: a 10 year retrospective study in the paediatric population with a review of the literature. J Otolaryngol. 1989 June;18(4):168-72.

2. Fosini P, Picarella G, De Campora E. Antrochoanal polyp: analysis of 200 cases. Acta Otolaryngologica Italica. 2009 Feb; 29(1):21-26

3. Basu SK, Bandyopadhyay SN, Bora H. Bilateral Antrochoanal polyps. J Laryngol Otol. 2001 Jul; 115 (7): 561-2.

4. Markov D, Drajina Z, Pole G. Nasal polyps in children. Acta Med Croatica. 1999; 53(2):97-99.

5. Chung SK, Chang BC, Dhong HJ. Surgical, radiologic and histologic findings of Antrochoanal polyp. Am J Rhinol. 2002 Mar-Apr;16(2):71-76.

6. Yilmaz YF, Titiz A, Ozcan M, Tezer MS, Ozlugedik S, Unal A. Bilateral antrochoanal polyps in an adult: a case report. $B$-ENT. $2007 ; 3(2): 97-9$

7. Konstantinidis I, Tsakiropoulou E, Vital I, Vital V, Constantinidis J. Bilateral antrochoanal polyps originated from inferior meatal antrostomies. Laryngorhinootologie. 2008 Jun;87(6):417-9. Epub 2008 Jan 24.

8. Myatt HM, Cabrera M. Bilateral antrochoanal polyps in a child; a case report. J Laryngol Otol. 1996 March;110(3):272-4.

9. Weissman JL, Tabor EK, Curtin HD. Sphenochoanal polyps. Evaluation with CT and MRI imaging Radiology. 1991 Jan; 178(1): 145-8.

10. Cook PR, Davis WE, MCDonald R, McKinsey JP. Antrochoanal polposis- a review of 33 cases. ENT J 1993 Jun; 72(6): 401-402, 404-410.

11. El Guindy A, Mansour MH. The role of transcanine surgery in antrochoanal polyps. J Laryngol Otol 1994 Dec; 108 (12): 1055-1057.

12. Ophir D, Marshack G. Removal of antral polyp through an extended nasoantral window. Laryngoscope 1987 Nov; 97 (11):1356-1357.

13. Woolley AL, Clary RA, Lusk RP. Antrochoanal polyp in children. Am J Oto Laryngol. 1996 Nov-Dec: 17(6): 368-373.

14. Vleming M, De Vries N. Endoscopic sinus surgery for antrochoanal pol-yps. Rhinology 1991; Mar. 29 (1) $77-8$.

15. Ta-Jen Lee, Shiang-Fu Huang. Endoscopic sinus surgery for antrochoanal polyps in children. Otolaryngol Head Neck Surg 2006;135:688-92.

16. Hong SK, Min YG, Kin CT, Byun SW. Endoscopic removal of the antral portion of antro-choana polyp by powered instrumentation. Laryngoscope 2001 October; 111 (10): 1774-8. 